\title{
The Analysis and Evaluation for the Development Environment of Yangluo Port
}

\author{
Mei Zhang, Chengxuan Cao \\ State Key Laboratory of Rail Traffic Control and Safety, Beijing Jiaotong University, Beijing 100044, \\ P.R. China
}

Keywords: evaluation matrix, development environment, Fuzzy Analytic Hierarchy Process,Port, the fuzzy judgmentmatrix.

\begin{abstract}
The development environment of Yangluo Port will influence the port's development strategy. This paper applies the FuzzyAnalytic Hierarchy Process (FAHP) to the evaluation of port's development environment, and provides a mathematical model about it, then gives the formula of weight.Through making up the evaluation matrix of inner and external factors, it quantifies the advantages and disadvantages as well as the opportunities and threats the port faced with .Thus it gets the conclusion that Yangluo Port should adopt the growing development strategy.
\end{abstract}

\section{Introduction}

The environment is of great significance to the promotion of the port's further development. This paperapplies the FAHP to evaluate the internal and external environment of Yangluo port. In this evaluation process,we mainly calculate the weight of environmental factor.In fact,many methods were proposed for the calculation of the weight in the literature and many scholars applied the Analytic Hierarchy Process (AHP) analysis to deal with the weight[1-6].

Althoughsome scholars have made some achievements on the study of Yangluo port's development,a majority of articles adopted the AHP analysis to solve the problemsof Yangluo port's development. AHP method is greatly influenced by the subjective thinking. The results tend to be crudeand it is hardly convincing.In this paper, we combine the AHP with the fuzzy mathematics[7-10]when calculating the weight,which makes the results more reasonable.

\section{The port's analysis of the development environment}

The port's analysis of the strengths and weaknesses

Internal factors including strengths and weaknesses in Table 1.

Table1Internal factors including strengths and weaknesses

\begin{tabular}{|c|l|}
\hline \multirow{3}{*}{$\begin{array}{c}\text { strengths } \\
\text { B1 }\end{array}$} & $\begin{array}{l}\text { C1: } \text { C2:Forming integrated logistics service network; } \\
\text { C3:Excellent deep-water coastline and good deep-water Channel; } \\
\text { C4:Having a prosperous port-vicinity industry. }\end{array}$ \\
\hline \multirow{3}{*}{ weaknesses } & $\begin{array}{l}\text { D1:The infrastructure and service ability is poor; } \\
\text { D2:The level of integration of resources and rational utilization rate is not high; } \\
\text { D2:The Informatization level is not high; } \\
\text { D2 }\end{array}$ \\
& D4: The management level needs to be strengthened. \\
\hline
\end{tabular}

Evaluation and analysis of the various factors,methodsare presented as follows:

Tableting hierarchies:Thetargetlayers is the development of Yangluoport,guidelines layers are the strengths and weaknesses of port enterprises,program layers is a key factor already identified . 
Structure fuzzy judgment matrix: Compare each relevant element separately and mark it,Here we refer the importance as $r_{i j}$,the values are as follows: $1 r_{i j}=0.5$, meaning that two factors $a_{i}$ and $a_{j}$ are of equal importance; (2) $0 \leq r_{i j}<0.5$,meaning that $a_{j}$ is more important than $a_{i}$; (3) $0.5<r_{i j} \leq 1$,meaning that $a_{i}$ is more important than $a_{j}$. According to a number of indicators of the intermediate layer,we can get several judgment matrix. First,we should structure the fuzzy judgment matrix. Generally,we adopt 0.1-0.9 scale to measure them. The results are listed as Table 2.

Table 2 The definition of $r_{i j}$

\begin{tabular}{|c|c|}
\hline Scaling & Meaning \\
\hline 0.5 & Compared to two factors, it is equally important \\
\hline 0.6 & One factor is a little important than the other \\
\hline 0.7 & One factor isobviously more important than the other \\
\hline 0.8 & One factor is strongly more important than the other \\
\hline 0.9 & One factor is extremely more important than the other \\
\hline
\end{tabular}

Second,transforming the fuzzy judgment matrix to fuzzy consistent matrix,the transformation formula is:

$$
r_{i}=\sum_{k=1}^{m} f_{i k}, i=1,2, \cdots \cdots, m \quad \text { (1) } r_{i j}=\left(r_{i}-r_{j}\right) / 2 n+0.5, i=1,2, \cdots \cdots m,
$$

Finally,calculating the value of the weight of each index,the formula is

$$
l_{i}=\sum_{j=1}^{m} r_{i j}-0.5, i=1,2, \cdots \cdots m(3) w_{i}=2 l_{i} / m(m-1), i=1,2, \cdots \cdots m
$$

The results are as follows:

The fuzzy judgment matrixA $\rightarrow \mathrm{B}:$

$$
A=\left[\begin{array}{ll}
0.5 & 0.6 \\
0.4 & 0.5
\end{array}\right]
$$

The fuzzy consistent matrix $\quad \mathrm{A} \rightarrow \mathrm{B}$ :

$$
A=\left[\begin{array}{ll}
0.5 & 0.55 \\
0.45 & 0.5
\end{array}\right]
$$

The fuzzy judgmentmatrix of strengths $B_{1} \rightarrow \mathrm{C}$ :

$$
B_{1}=\left[\begin{array}{llll}
0.5 & 0.4 & 0.3 & 0.4 \\
0.6 & 0.5 & 0.4 & 0.6 \\
0.7 & 0.6 & 0.5 & 0.4 \\
0.6 & 0.4 & 0.6 & 0.5
\end{array}\right]
$$

The fuzzy consistent matrix $\quad B_{1} \rightarrow \mathrm{C}$ : 


$$
B_{1}=\left[\begin{array}{llll}
0.5 & 0.4375 & 0.425 & 0.4375 \\
0.5625 & 0.5 & 0.4875 & 0.5 \\
0.575 & 0.5125 & 0.5 & 0.5125 \\
0.5625 & 0.5 & 0.4875 & 0.5
\end{array}\right]
$$

The fuzzy judgmentmatrix of weaknesses $\quad B_{2} \rightarrow \mathrm{D}$

$$
B_{2}=\left[\begin{array}{llll}
0.5 & 0.6 & 0.3 & 0.6 \\
0.4 & 0.5 & 0.6 & 0.8 \\
0.7 & 0.4 & 0.5 & 0.6 \\
0.4 & 0.2 & 0.4 & 0.5
\end{array}\right]
$$

The fuzzy consistent matrix $\quad B_{2} \rightarrow \mathrm{D}$

$$
B_{2}=\left[\begin{array}{llll}
0.5 & 0.4625 & 0.475 & 0.5625 \\
0.5375 & 0.5 & 0.5125 & 0.6 \\
0.525 & 0.4875 & 0.5 & 0.5875 \\
0.4375 & 0.4 & 0.4125 & 0.5
\end{array}\right]
$$

Then,we calculate the total weight of each index to the target,thus we get the Internal Factor Evaluation(IFE) matrixshow in Table 3.

Table 3IFEmatrix

\begin{tabular}{|c|c|c|c|c|}
\hline & Key internal factors & Weight & Score & Weighted score \\
\hline \multirow{3}{*}{$\begin{array}{c}\text { Strengths } \\
\left(B_{1}\right)\end{array}$} & C1 & 0.1192 & 4 & 0.4768 \\
\cline { 2 - 5 } & C2 & 0.1421 & 4 & 0.5684 \\
\cline { 2 - 5 } & C3 & 0.1467 & 4 & 0.5868 \\
\hline \multirow{3}{*}{$\begin{array}{l}\text { Weakness } \\
\left(B_{2}\right)\end{array}$} & C4 & 0.1421 & 4 & 0.5684 \\
\cline { 2 - 5 } & D2 & 0.1125 & 2 & 0.2250 \\
\hline \multirow{2}{*}{\begin{tabular}{c}
$*$ \\
\cline { 2 - 5 }
\end{tabular}} & D3 & 0.1238 & 1 & 0.1238 \\
\hline
\end{tabular}

The port's analysis of the opportunities and threat

With the same method we can get the External Factor Evaluation(EFE) matrix show in Table 4 and Table 5.

Table 4 Internal factors including opportunities and threat

\begin{tabular}{|l|l|}
\hline & \\
\hline \multirow{3}{*}{ Opportunities } & C1: The construction opportunities of Yangtze \\
& River waterway; \\
& C2: The rapid development of the port industry; \\
& C3: Port cooperation is the realistic need. \\
\hline
\end{tabular}




\begin{tabular}{|l|l|}
\hline Threat & $\begin{array}{l}\text { D1:The domestic economic is slowing down; } \\
\text { D2:The competition between ports is becoming } \\
\text { more and more fierce; } \\
\text { D3:The development of the logistics industry leads } \\
\text { to cargo diversion. }\end{array}$ \\
\hline
\end{tabular}

Table 5EFEmatrix

\begin{tabular}{|c|c|c|c|c|}
\hline \multirow{3}{*}{ Opportunities } & key external factors & weight & score & weighted score \\
\cline { 2 - 5 } & C1 & 0.2019 & 4 & 0.8076 \\
\cline { 2 - 5 } & C2 & 0.1832 & 4 & 0.7328 \\
\hline \multirow{3}{*}{ Threat } & C3 & 0.1711 & 3 & 0.5133 \\
\cline { 2 - 5 } & D1 & 0.1499 & 1 & 0.1499 \\
\cline { 2 - 5 } & D2 & 0.135 & 2 & 0.2700 \\
\hline & D3 & 0.1652 & 2 & 0.3304 \\
\hline
\end{tabular}

Through the analysis above we can easily know that the total score of Yangluo port's IFEmatrix is 2.8539,and the EFE matrix is 2.804. Both are greater than 2.5, that means that means Yangluoport is in a dominant position and opportunities outweigh the threats, so we get the conclusion that Yangluo Port should adopt the growing development strategy.

\section{Conclusions}

TheFAHP analysis is a systematic method, which it is simple and has potential application to evaluate the port development. The FAHP has advantage to analyze the complex evaluation problem mathematically.

In this paper, we mainly deal with the following problems:

(1) Confirming the main factors affecting the port's development;

(2) Combining the AHP with the fuzzy mathematics andestablishing several fuzzy judgment matrix toconfirm each index's weight;

(3) With the experts' estimation,we get the weighted score, which can decide the final result.

\section{Acknowledgements}

This research was supported in part by the National Basic Research Program of China (Grant No. 2012CB725400), the National Natural Science Foundation of China (Grant No. 71131001-1), and the Research Foundation of State Key Laboratory of Rail Traffic Control and Safety, Beijing Jiaotong University, China (Grant No. RCS2014ZT19).

\section{References}

[1] Jia, S.,Ecological assessment and analysis about the port planning.Environmental Management of China,2010(2).

[2] Wang, S., Wuhan Newport's research of development strategy.Wuhan University of Technology, 2008.

[3] Wang, S. and Zhang, X., SWOT analysis of Wuhan Newport's development.Science and Technology of Ports,2010(3). 
[4] OOCL honored by Port of Long Beach for Environment efforts.http://www.oocl.com/schi/aboutoocl/corporatemessages/2007/24apr2007.2007(4)

[5] W.Peng, W. and Jiang, H., Accelerate the construction of Wuhan Newport Promote regional logisticsdevelopment in Wuhan, Transportation Enterprise Management,2011(7).

[6] Sun, J. and Jiang, D., Consistent method to construct judgment matrix in AHP analysis.Journal of Southeast University,1991,21(3):69 75.

[7] Zhang, J., Comparison of the three ranking methods for the fuzzy consistent judgmentmatrix. Systems Engineering and Electronics,2003,25(11):79-85.

[8] Zhang, J., Fuzzy analytical hierarchy process. Fuzzy Systems and Mathematics,2000,14(2):80-88.

[9] Lan, J. and Yang, J., The weight of fuzzy analytic hierarchy process study.Systems Engineering-theory\&Practice,2006,26(9).

[10]Saaty, T.L., Modeling unstructured decision problems. The Theory of Analytical Hierarchies,1978. 